\title{
RESIDUAL FATIGUE LIFE ESTIMATION OF CRACKED AIRCRAFT STRUCTURAL COMPONENTS UNDER LOAD SPECTRUM
}

\author{
Katarina Maksimovic ${ }^{1}$, Slobodanka Boljanovic ${ }^{2}$, Mina Djuric ${ }^{3}$, Ivana Vasovic \\ Maksimovic $^{4 *}$, Mirko Maksimovic ${ }^{5}$
}

${ }^{1}$ Secretariat for Utilities and Housing Services Water Management, 1 Kraljice Marije Street, Belgrade, Serbia

e-mail: kmaksimovic@mts.rs

${ }^{2}$ Mathematical Institute of SASA, 35 Kneza Mihaila Street, Belgrade, Serbia e-mail: Slobodanka.boljanovic@gmail.com

${ }^{3}$ Military Technical Institute, 1 Ratka Resanovica Street, Belgrade, Serbia e-mail: minadjuric12@gmail.com

${ }^{4}$ Research and Development Institute Lola Ltd, 70a Kneza Viseslava Street, Belgrade, Serbia e-mail: ivanavvasovic@gmail.com

${ }^{5}$ PUC Belgrade Waterworks and Sewerage, 27 Kneza Milosa Street, Belgrade, Serbia e-mail: maksimovic.mirko@gmail.com

*corresponding author

\begin{abstract}
This work deals with fatigue behaviour of cracked aircraft structural components under cyclic loads of constant amplitudes and load spectrum. This investigation is focused on developing efficient and reliable computational methods for fatigue life estimation of cracked aircraft lugs under cyclic loads of constant amplitude and load spectrum. For crack growth analyses and residual lives of damaged lugs two approaches are used: the Strain Energy Density (SED) method and the conventional Forman`s method. A special attention has been focused on the determination of the fracture mechanics parameters of structural components such as stress intensity factors of aircraft cracked lugs. The effects of the shape of lug surface cracks on the residual fatigue life are investigated as well. The SED method uses the low-cycle fatigue (LCF) properties of the material, which are also used for the lifetime evaluation until the occurrence of final failure. Therefore, the experimentally obtained dynamic properties of the material such as Forman`s constants are not required when this approach is concerned. The complete computational procedure for the crack propagation analysis using low-cycle fatigue material properties is illustrated with the cracked structural elements. To determine analytic expressions for stress intensity factors (SIF), singular finite elements are used. The results of the numerical simulations for crack propagation based on the strain energy density method have been compared with the authors' experimental results.
\end{abstract}

Keywords: fatigue, crack growth, load spectrum, singular finite elements, lifetime 


\section{Introduction}

Many structural components are subjected to cyclic loading. In these components, fatigue damage is the prime factor in affecting structural integrity and service life. Fatigue damage is typically divided into three stages: crack initiation, crack propagation and final failure. These three stages are important in determining the fatigue life of structural components.

Primary attention in this research has been to develop an efficient and reliable computational method for residual life estimation of damaged structural components under cyclic loading. To determine residual life of damaged structural components two crack growth methods are used: conventional Forman`s crack growth method and crack growth model based on the strain energy density method. The latter method uses the low cycle fatigue properties in the crack growth model. The governing equations for both crack initiation and crack growth phase using conventional crack growth and SED are given in Maksimović Set al. (2011); Maksimović S. et al. (2012) and Sehitoglu H. et al. (1996). The ability to successfully maintain aircraft airworthiness and structural integrity is critically dependent on the application of appropriate fatigue crack growth (FCG) prediction tools. The prediction tools are required to accurately predict FCG in aircraft structures and components under flight spectrum loading, and thus reliably provide total economic lives or inspection intervals as part of a stringent aircraft structural integrity management plan.

Fatigue crack growth in aircraft structures and components under flight spectrum loading is traditionally predicted based on FCG rates obtained from constant-amplitude (CA) crack growth testing using the cycle-by-cycle approaches (Blažić M. et al. 2011; Maksimović M. et al. 2012).

\section{Fatigue crack growth method model based on strain energy method}

In this work, fatigue crack growth method based on energy concept is considered and it is necessary to determine the energy absorbed till failure. This energy can be calculated by using cyclic stress-strain curve. As a result, the energy absorbed till failure becomes (Maksimović M. et al. 2018):

$$
W_{e}=\frac{4}{1+n^{\prime}} \sigma_{f}^{\prime} \varepsilon_{f}^{\prime}
$$

where $\sigma_{\mathrm{f}}^{\prime}$ is cyclic yield strength and $\varepsilon_{\mathrm{f}}^{\prime}-$ fatigue ductility coefficient. Fatigue crack growth rate can be obtained in the next form (Maksimović M. et al. 2018; Boljanović S. et al. 2014):

$$
\frac{d a}{d N}=\frac{\left(1-n^{\prime}\right) \psi}{4 E I_{n^{\prime}} \sigma_{f}^{\prime} \varepsilon_{f}^{\prime}}\left(\Delta K_{I}-\Delta K_{t h}\right)^{2}
$$

where $\Delta \mathrm{K}_{\mathrm{I}}$ is the range of stress intensity factor, $\psi$ - constant depending on the strain hardening exponent $\mathrm{n}^{\prime}, \mathrm{I}_{\mathrm{n}}{ }^{\prime}$ - the non-dimensional parameter depending on $\Delta \mathrm{K}_{\mathrm{th}}$ is the range of threshold stress intensity factor and is function of stress ratio i.e.

$$
\Delta K_{t h}=\Delta K_{t h 0}(1-R)^{\gamma}
$$

$\Delta K_{\text {tho }}$ is the range of threshold stress intensity factor for the stress ratio $\mathrm{R}=0$ and $\gamma$ is coefficient (usually, $\gamma=0.71$ ). Equation (2) enables us to determine crack growth life of different structural component. Very important fact is that equation (2) is easy for application since low cyclic material properties $\left(\mathrm{n}^{\prime}, \sigma_{\mathrm{f}}^{\prime}, \varepsilon_{\mathrm{f}}\right)$ are used as parameters. 
For comparisons computation results based on SED we used conventional Forman`s crack growth method too in the next form

$$
\frac{d a}{d N}=\frac{C(\Delta K)^{n}}{(1-R) K_{C}-\Delta K}
$$

where: $\mathrm{C}, \mathrm{n}$ are crack growth rate constant and exponent, $\mathrm{R}$ is stress ratio, $\mathrm{K}_{\mathrm{C}}$ is fracture toughness and $\Delta \mathrm{K}$ is the range of stress intensity factor. For tension-compression cyclic load cases, the following Elber rate model is adopted:

$$
\frac{d a}{d N}=C\left[(1-R)^{q} K_{\max }\right]^{n}, R \leq R_{c u t^{-}}, R \leq R_{c u t^{-}}
$$

where $\mathrm{R}_{\text {cut }}{ }^{-}$is the cut-off value of the negative stress ratio. In the previous equation, the exponent $\mathrm{q}$ is considered as the acceleration index (Chang, JB et al. 1981).

\section{Crack growth analysis of cracked aircraft skin/plate under load spectrum}

Here, we illustrated numerical simulation of crack growth method using strain energy density method (SED). Geometry of cracked aircraft skin is shown in Figure 1. Material of aircraft skin is aluminium alloy 2219-T851. Low cyclic material properties of aluminium alloy 2219-T851 are: $\sigma_{\mathrm{f}}^{\prime}=613 \mathrm{MPa} ; \varepsilon_{\mathrm{f}}^{\prime}=0.35 ; \mathrm{n}^{\prime}=0.121 ; \mathrm{k}^{\prime}=710 \mathrm{MPa} ; \mathrm{S}_{\mathrm{y}}{ }^{\prime}=334 \mathrm{MPa} ; \mathrm{E}=7110^{3} \mathrm{MPa} ; \Delta \mathrm{K}_{\text {th } 0}$ $=30 ; \mathrm{I}_{\mathrm{n}}{ }^{\prime}=3.067 ; \psi=0.95152, \mathrm{~K}_{\mathrm{c}}=71.5 \mathrm{MPa} \sqrt{\mathrm{m}}_{\mathrm{m}}$. Detail computation residual life estimation of cracked skin for various load spectra are given in Table 1. Computation results are compared with available experimental results according to Chang J. B. et al. (1981). Good agreement of present numerical results with experiments is evident.

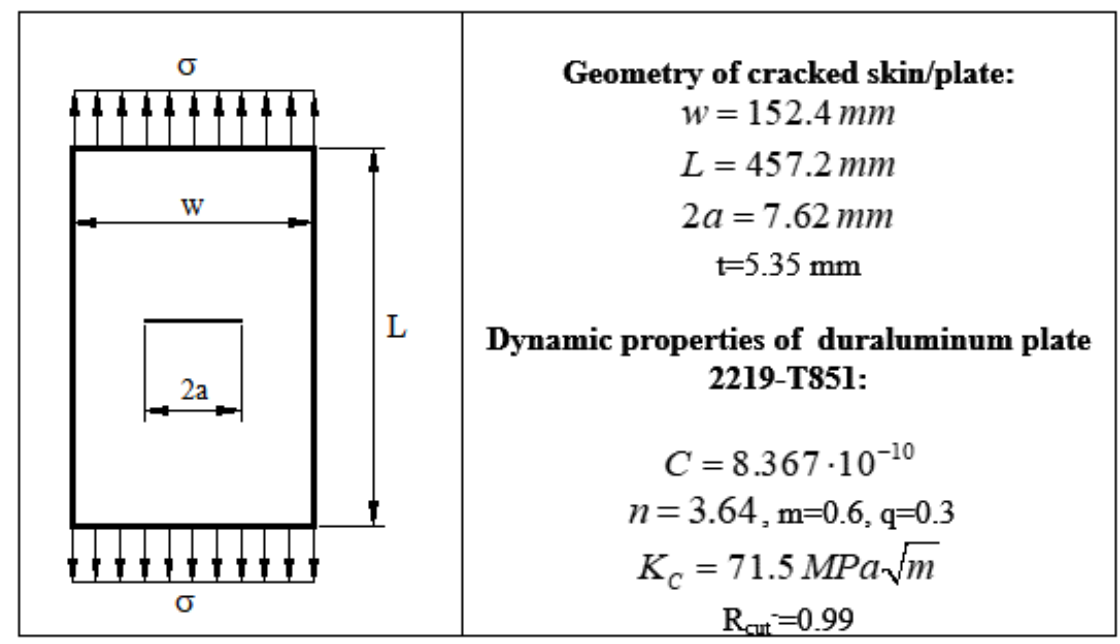

Fig. 1. Model of skin/plate panel with initial crack 


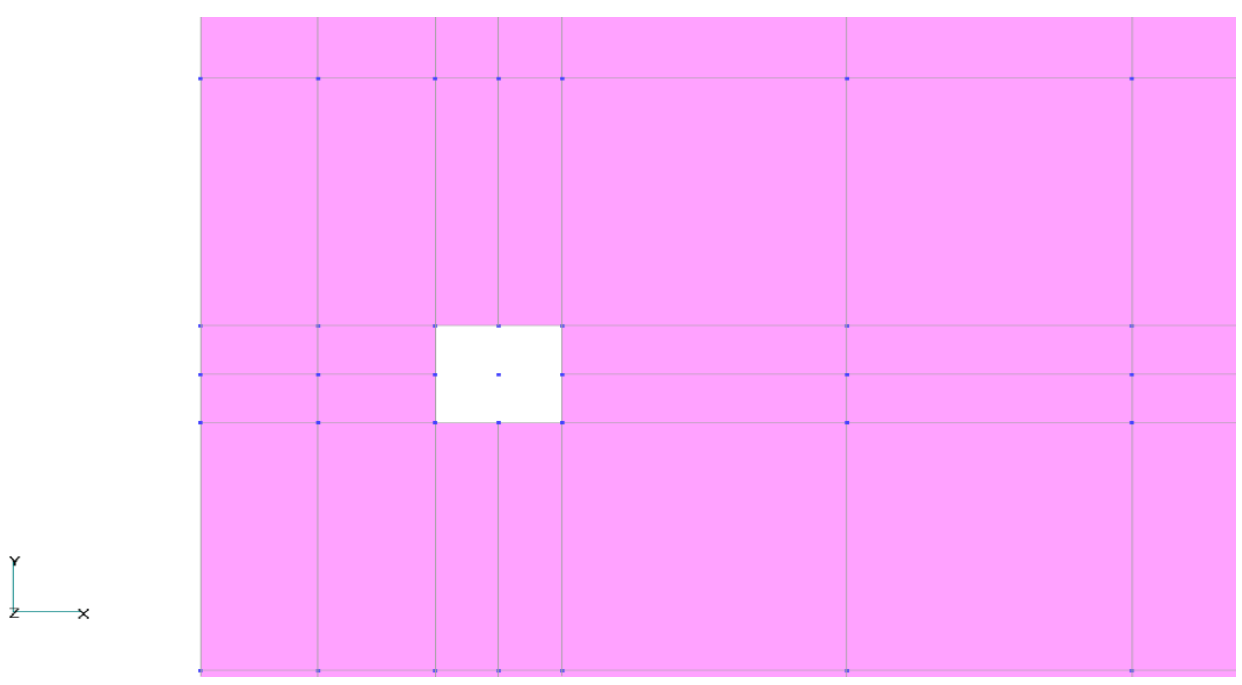

Fig. 2. Finite element model of skin/plate with initial crack and "super-element" around crack tip

In Figure 2, finite element model of cracked part panel is shown. To obtain precise stress intensity factors special "super-element" with 6-node singular finite elements around initial crack tip is used.

\begin{tabular}{|c|c|c|c|c|c|}
\hline $\begin{array}{c}\text { Specimen } \\
\text { No. }\end{array}$ & $\begin{array}{c}\sigma_{\max } \\
{[M P a]}\end{array}$ & $\begin{array}{c}\sigma_{\min } \\
{[M P a]}\end{array}$ & $\begin{array}{c}\text { Experiment } \\
\mathrm{N}_{\mathrm{f}}^{\text {exp }}\end{array}$ & $\begin{array}{c}\text { Computation } \\
\text { results(eq.2) } \\
\mathrm{N}_{\mathrm{f}}^{\text {SED }}\end{array}$ & $\begin{array}{c}\text { Computation } \\
\text { results (eq.5) } \\
\mathrm{N}_{\mathrm{f}}^{\text {Elber }}\end{array}$ \\
\hline $\mathrm{M}-1$ & 55.16 & 0 & 355810 & 370530 & 339000 \\
\hline $\mathrm{M}-3$ & 55.16 & -55.16 & 129240 & 126324 & 96000 \\
\hline $\mathrm{M}-4$ & 55.16 & -16.55 & 144000 & 138912 & \\
\hline $\mathrm{M}-5$ & 275.8 & 0 & 846 & 701 & 803 \\
\hline $\mathrm{M}-6$ & 275.8 & 82.74 & 1695 & 1927 & 1537 \\
\hline $\mathrm{M}-7$ & 275.8 & 193.06 & 14870 & 13346 & 7200 \\
\hline $\mathrm{M}-8$ & 275.8 & -27.58 & 409 & 447 & \\
\hline $\mathrm{M}-9$ & 55.16 & -5.516 & 175000 & 179552 & \\
\hline $\mathrm{M}-10$ & 275.8 & -82.74 & 251 & 143.5 & \\
\hline
\end{tabular}

Table 1. Comparisons numerical crack growth model based on Strain Energy Density Method (SED) with experiments for cyclic load of constant amplitude

In Table 1, due to a systematic approach, in addition to the computation estimates based on SED and calculation results of the evaluation with conventional laws of crack growth here modified Elber`s crack growth law in which the fatigue crack growth properties of dynamic characteristics material are used. 


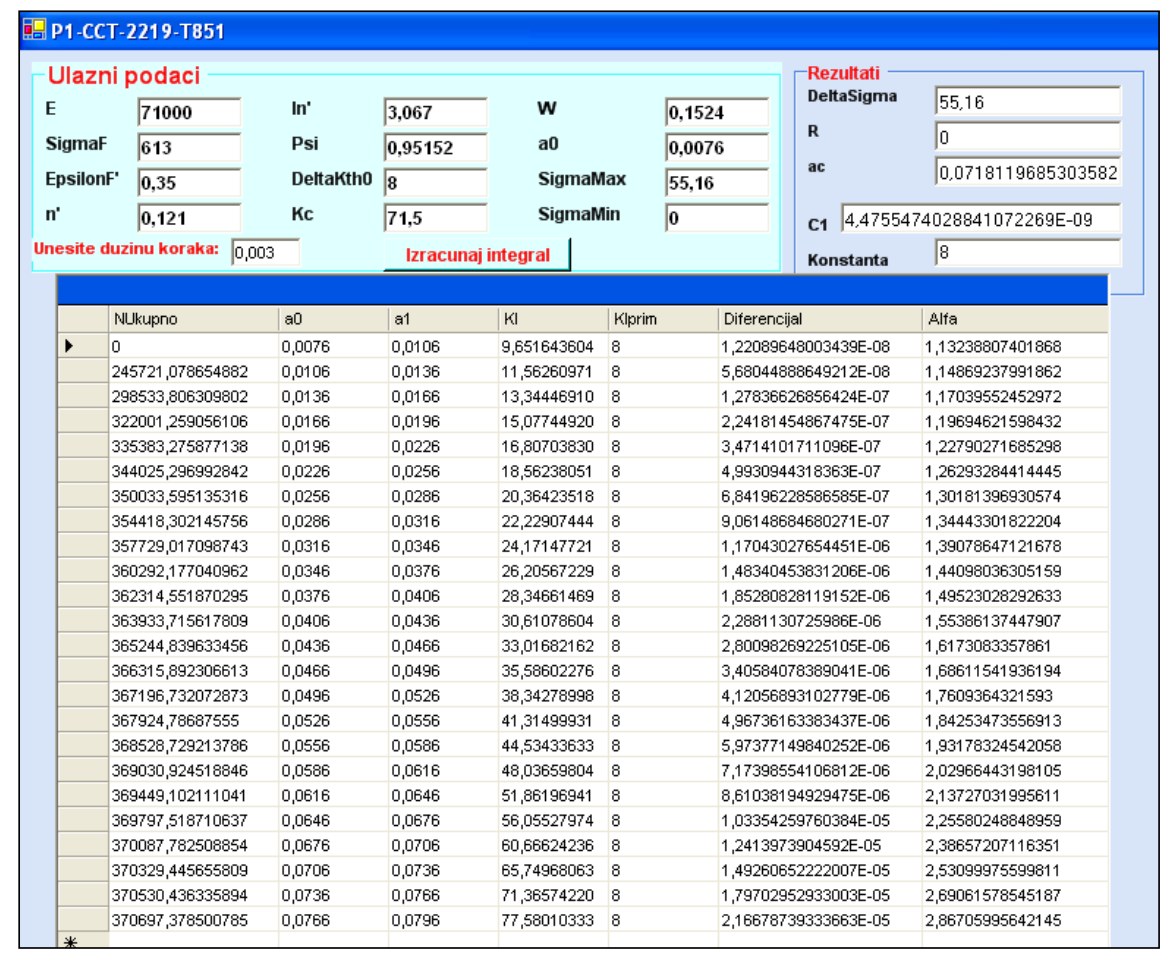

Table 2. Results of residual life estimation of cracked specimen M-1

In Table 2 are given the complete computation residual life results which include relation, a-N, (a- crack length, $\mathrm{N}$ - is the number of cycles). These results are obtained using in-house software "SED" based on Strain Energy Density Method (Maksimovic S. and Maksimovic K. 2012; Boljanović S. and Maksimović, S. 2014; Chang, J. B. et al. 1981; Maksimović, S. 2008; Maksimović K. et al. 2011; Boljanović S. et al. 2019).

In Figure 3 graphical crack growth behaviour of cracked panel under tension cyclic load is shown. 


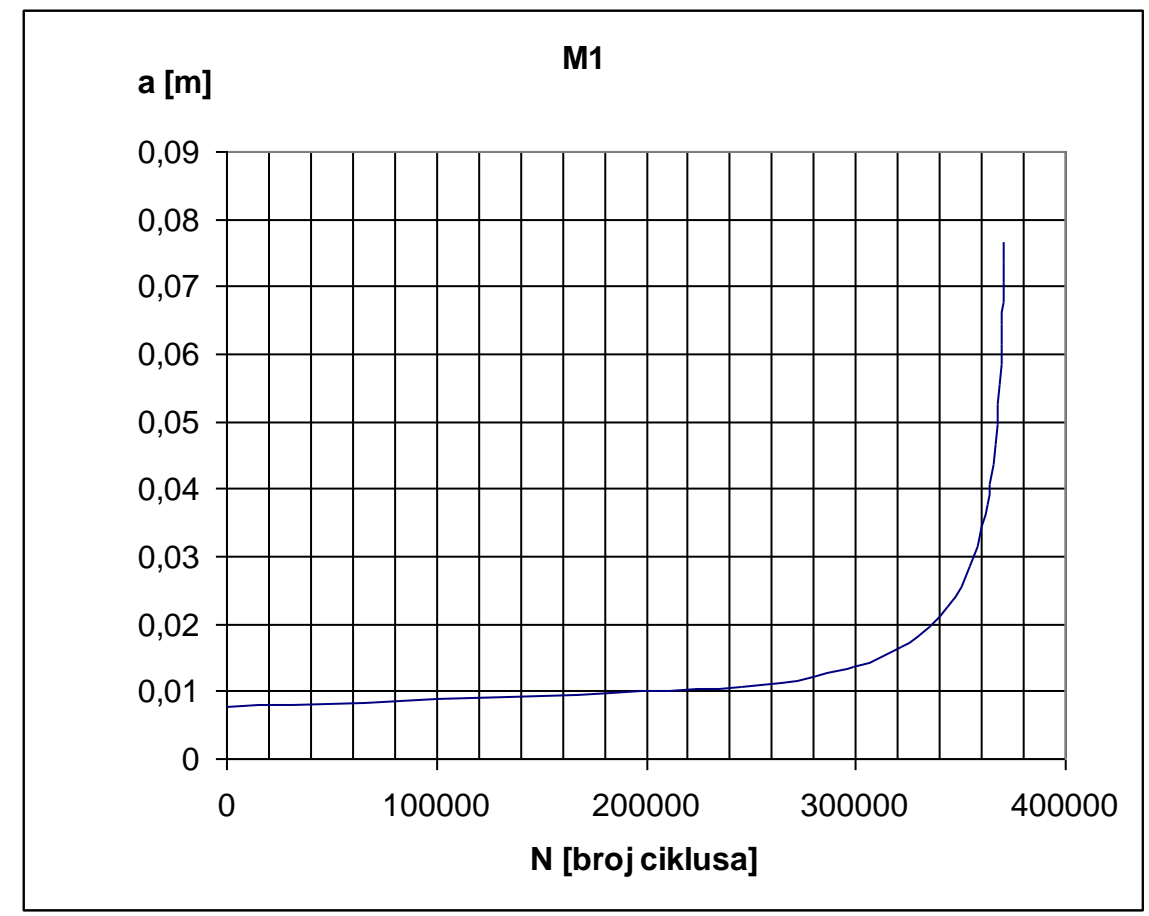

Fig. 3. Dependence a-N for specimen M-1 using SED under cyclic loads of constant amplitude

In Table 3 are shown residual life estimations of cracked plate/shell panel under multiple overload/underload spectrum. Good agreement of the present computation with experimental results is evident, according to Chang, J. B. et al. (1981).

\begin{tabular}{|c|c|c|c|c|c|c|c|c|c|}
\hline $\begin{array}{l}\text { Type } \\
\text { of } \\
\text { speci- } \\
\text { men }\end{array}$ & $\begin{array}{c}\text { Loading } \\
\text { profile }\end{array}$ & $\begin{array}{c}\sigma_{\max }^{I} \\
{[M P a]}\end{array}$ & $\begin{array}{c}\sigma_{\min }^{I} \\
{[M P a]}\end{array}$ & $\begin{array}{c}\sigma_{\max }^{I I} \\
{[M P a]}\end{array}$ & $\begin{array}{c}\sigma_{\min }^{I I} \\
{[M P a]}\end{array}$ & $\begin{array}{c}\mathrm{N}_{\mathrm{I}} \\
\text { cycles }\end{array}$ & $\begin{array}{c}\mathrm{N}_{\mathrm{II}} \\
\text { cycles }\end{array}$ & $N_{f}^{\exp }$ & $\begin{array}{c}\text { Numerical } \\
\text { solution } \\
(\text { SED) }\end{array}$ \\
\hline M-31 & & 55.16 & 0 & 137.9 & 0 & $\begin{array}{c}1000 \\
0\end{array}$ & $\begin{array}{c}\text { to } \\
\text { failure }\end{array}$ & 22430 & $\begin{array}{c}(21140) \\
22262\end{array}$ \\
\hline M-32 & AMMW & 137.9 & 0 & 275.8 & 0 & 5000 & $\begin{array}{c}\text { to } \\
\text { failure }\end{array}$ & 5275 & $\begin{array}{c}5476) \\
5131\end{array}$ \\
\hline M-33 & & 55.16 & 16.55 & 137.9 & 16.55 & $\begin{array}{c}1000 \\
0 \\
\end{array}$ & $\begin{array}{c}\text { to } \\
\text { failure }\end{array}$ & 27000 & 27943 \\
\hline M-34 & & 137.9 & 41.37 & 275.8 & 82.74 & 5000 & $\begin{array}{l}\text { to } \\
\text { failure }\end{array}$ & 6884 & 6462 \\
\hline
\end{tabular}

Table 3. Multiple overload/underload test descriptions and crack growth correlation: Comparisons Numerical results with experiments

\section{Conclusion}

This work presents a computational model/procedure for assessing the residual strength of damaged aircraft structural components subjected to cyclic loading. A special aspect of this investigation is based on application of Strain Energy Density (SED) method in residual life 
estimation of structural components with initial cracks under load spectrum. In this approach, we used the same low cyclic material properties for crack growth and crack initiation. For determination low cyclic fatigue properties of materials and corresponding parameters of fracture mechanics including fatigue tests of representative aircraft structural components such as cracked aircraft skin are used. To validate computation methods in residual life estimation of cracked structural elements modified conventional crack growth method is used too. The computation procedures for residual life estimations of cracked structural elements these are compared with corresponding experimental tests. Good agreement between computation and experimental results are obtained (Tables 1 and 3). This approach can be used as efficient computation method in total fatigue life estimations of structural element under cyclic loads.

This work was partially supported by the Ministry of Education, Science and Technological Developments of Serbia under projects ON 174001 and TR-35024.

\section{References}

Boljanović S, Maksimović S (2014). Fatigue Crack Growth Modeling of Attachment Lugs. International Journal of Fatigue 58, 66-74.

Boljanović S, Maksimović S, Carpnteri A., Ćosić M. (2019). Fatigue endurance of plates with two semicircular edge notches and one quarter-elliptical corner crack or through-thethickness crack, International Journal of Fatigue 127, 45-52.

Blažić M, Maksimović K, Assoul J (2011). Determination of Stress Intensity Factors of Structural Elements by Surface Cracks, in Proceedings IConSSS 2011 The Third International Congress of Serbian Society of Mechanics, Vlasina Lake (Serbia), 5-8 July 2011. pp. 374382. ISBN 978-86-909973-4-3.

Chang JB, Engle RM, Stolpestad J (1981). Fatigue Crack Growth Behavior and Life Predictions for 2219-T851 Aluminum Subjected to Variable-Amplitude Loadings, ASTM STP 743, 1981.

Maksimović K, Stamenković D, Boljanović S, Maksimović M, Vasović I (2017). Modeling Fracture Mechanics Parameters of Cracked Structural Elements Under Thermomechanical Loads, 13th International Conference on Accomplishments in Mechanical and Industrial Engineering, 26-27 May 2017. Banja Luka, Republic of Srpska, ISBN 978-99938-39-73-6

Maksimović M., Nikolić-Stanojević V, Maksimović K, Stupar S (2012). Damage Tolerance Analysis of Structural Components Under General Load Spectrum, TEHNICKI VJESNIKTECHNICAL GAZETTE, vol. 19 br. 4, pp. 931-938.

Maksimović M, Vasović I, Maksimović K, Trišović N, Maksimović S (2018). Residual Life Estimation of Cracked Structural Components, FME Transactions, pp. 124-128; doi: $10.5937 /$ fmet $1801124 \mathrm{M}$.

Maksimović S (2018). Life assessment methods of initial damaged structures under general loading spectrum, IFMASS 10 Fundamentals of fracture mechanics and structural integrity assessment methods 23-26 June.

Maksimovic S, Maksimovic K (2012). Improved Computation Method in Residual Life Estimation of Structural Components, Theoretical and Applied Mechanics, Special IssueAddress to Mechanics, Vol. 40, No. 2, pp. 247-261, Belgrade.

Maksimović S, Posavljak S, Maksimović K, Nikolic-Stanojević V, and Djurković V (2011). Total Fatigue Life Estimation of Notched Structural Components Using Low-Cycle Fatigue Properties, STRAIN An Int Journal for Experimental Mechanics, Volume 47, Issue Supplement S2, pp 341-349.

Sehitoglu H, Gall K, Garcia AM (1996). Recent advances in fatigue crack growth modeling, Int J Fract., 80, pp. 165-192. 